\title{
Por que a
}

\section{conversação não é a alma da}

\section{democracia?}

\section{RESUMO}

A partir sobretudo dos textos de John Dewey nos estudos de comunicação, diz-se freqüentemente que a conversação facea-face é a alma da vida democrática. Mas a conversação tem sido muito mais honrada em aristocracias do que em democracias; e existem, de fato, dois distintos e contrários ideais de conversação: a conversação sociável e a conversação que "resolve-problemas".

\section{ABSTRACT}

Inspired by the writings of John Dewey, among others, communication studies have taken face-to-face conversation to be at the heart of democratic life. But face-to-face conversation has been much more honored in aristocracies than in democracies; and there are, in fact, two distinctive and contrasting ideals of conversation: the social conversation and the problem-solving conversation.

PALAVRAS-CHAVE / KEY WORDS

- Diálogo (Dialogue)

- Esfera Pública (Public Sphere)

- Argumentação (Argumentation)

\section{Michael Schudson}

Professor de Comunicação e Sociologia Universidade da Califórnia em San Diego (UCSD)
A CONVERSAÇÃo QUE SERVE a democracia é distinguida não pela igualdade, mas pelas normas governamentais e publicitárias, não pela espontaneidade mas pela civilidade e não pela sua prioridade ou superioridade para imprimir ou emitir média, mas sim pela necessária dependência existente entre eles. O argumento é oferecido para as instituições e para as normas da democracia para dar crescimento à conversação democrática antes que a conversação democrática dê crescimento às normas da democracia política e das instituições.

As noções da "sociedade civil" e da "esfera pública" levantaram a atenção para o caráter de "falar" como uma característica da constituição da democracia. Quando Jürgen Habermas escreve que "uma porção da esfera pública surge fazendo parte de cada conversação das assembléias individuais privadas, formando um corpo público" (1974, p. 79), a conversação está presa a uma excessivamente importante política. Se a democracia é, como tem sido chamada, um regime por meio da discussão, ou ainda mais precisamente "um regime pela racionalidade e liberdade de expressão pública em conjunto com a igualdade legal dos cidadãos", a conversação deve ser requisito básico para o funcionamento da democracia. ${ }^{1}$

Esta era certamente a visão de John Dewey. Para ele a fala era a característica central de uma vida democrática. A principal necessidade para revitalizar a vida pública, ele escreveu em 1927, é "o aprimoramento dos métodos e condições do debate, de discussão e de persuasão. Este é o problema do público". (Dewey,1927, p. 208).

Não obstante tão importante 
autoridade, aqui está algo que gostaria de criticar. Estando em espírito amigável, que então critico esta noção, em meu ponto de vista, muito apelativa. Mas também acredito que esta tem sido extraviada, talvez perigosamente.

\section{O lugar da conversação na democracia}

Não é preciso ir muito longe hoje em dia para encontrar visões do lugar da conversação no centro da vida democrática. O crítico literário David Simpson (1997) até mesmo fala sobre "o culto da conversação de hoje". Existe uma genuína obsessão com o termo. Isto pode ser encontrado por toda a paisagem acadêmica - na filosofia pós-modernista, nas críticas sociais comunitárias, no movimento do jornalismo público e em muitos outros lugares. É para ser encontrado na crítica liberal do meio populacional e na democracia discursiva de filósofos. Na crítica de Richard Rorty é principal a certeza do científico e do filosófico. O que nós podemos "saber", segundo Rorty, é somente o que podemos perceber durante uma conversação com outros, tanto quanto em um encontro com a natureza além da interação humana. Rorty, Michael Oakesshott e Hans George Gadamer compreendem a conversação como um modelo de conhecimento. Nós estamos vendo, observa Simpson, "a aparição da conversação ideal na cultura pós-moderna"(1995, p. 47).

Nos estudos da comunicação, James Carey tem sido especialmente eloqüente em colocar a conversação no centro da vida pública e na restauração de um público no coração do dever contemporâneo da sociedade democrática. O público é "um grupo de estranhos que se reúne para discutir o novo" (1995, p. 381). É "uma sociedade de conversações ou disputas dependentes da impressão para a disseminação de suas idéias"(1995, p. 381). Este era o grande ideal do público - que existiu na realidade, segundo a visão de Carey e também na de Habermas. Este "público de conversação", como Carey se refere, foi "um público de discussão e disputa independentemente da imprensa e do Estado" e que "tem sido tirado à força de nosso tempo"(1995, p. 383). No século $\mathrm{XX}$, como o jornalismo tornouse mais "objetivo", de acordo com suas luzes profissionais, o relacionamento da imprensa com o público se desintegrou. "A imprensa não mais facilitou ou animou uma conversação popular. Para o público a conversação desapareceu"(1995, p. 389). A imprensa já não era o pano de fundo do dever central da conversação, qualquer conversação permanecente "era conduzida pela imprensa em nome de um conhecimento superior e de instrumentos superiores para um inquérito sobre o que estava acontecendo"(1995, p. 389). Para Carey, o jornalismo independente fez o pior através da televisão, ajudou a destruir partidos políticos enquanto a opinião eleitoral ajudou a levar a obscuridade à genuína opinião política. A arena pública recuou, e os cidadãos tiveram uma pequena escolha a fazer: "absorver os políticos ou escapar deles" (1995, p. 391, ver também Carey, 1987).

Mas o que é - ou o que foi, ou o que será - este ideal de conversação na alma da vida democrática? Estamos nós a imaginá-lo como uma forma de vida social espontânea e livre? Isto poderá parecer uma parte importante que tomará a conversação como algo central. Mas será errado assumir que a espontaneidade é a autenticidade ou a verdade. A ênfase na retirada espontânea da atenção dos planos necessários para a democracia, e desta forma foi retirada do fato da democracia ser o plano. O meu argumento é de que a conversa democrática não é essencialmente espontânea, mas é essencialmente governada por regras e essencialmente civil, e diferentemente dos tipos de conversações que costumam manter alta a estima, a liberdade e a inteligência, é essencialmente orientada 
para resolver-problemas.

Devemos achar que a conversação é igualitária? Não necessariamente. Um indivíduo deve ter "capital cultura" para participar efetivamente de uma conversação. Deve até argumentar que o atual relacionamento da fala e da igualdade não é de afinidade mas um paradoxo. Por mais que a conversa seja entre verdades iguais, mais ela falha em fazer suposições claras, falha nas permissões estatais, falha em ser acessível a todos, até mesmo no silêncio.

A presunção da igualdade retira a atenção da conversação no seu fundamental problema dos membros da democracia, dos que entram e saem, e impede a atenção às regras que fazem a democracia possível tanto para pluralizar quanto para homogeneizar a população.

Eu gostaria de sugerir o que diferencia a conversação democrática. Não é a igualdade, mas a publicidade. A fala democrática não é necessariamente igualitária, mas essencialmente pública, e se isso significa que a fala democrática é aquela entre pessoas de diferentes valores e experiências, é também considerada profundamente desconfortável.

Idéias sobre conversação ocidental podem ser traçadas, no mínimo a partir de Cícero, o qual escreveu que a conversação privada deve ser mais amigável, livre de paixões e de fofocas sobre pessoas ausentes, e esta deve incluir e permitir a todos a sua vez. Seguindo Cícero, logo modernos italianos, franceses e ingleses advertiam a literatura de que a conversação havia estressado a cooperativa e igualado as características da conversação ideal. Interrupções, como os manuais franceses do século XVII repetiam insistentemente, estavam erradas, assim como o monopólio da conversação. Durante este mesmo tempo, a espontaneidade era encorajada, mesmo que ironicamente, por ter sido premeditada. Uma autoridade recomendou: "Hesitar mesmo com ocasional rigidez, com o intuito de preservar a ilusão da espontaneidade." 2

Mesmo assim, a advertência da espontaneidade estava dentro do contexto. Também havia advertências quanto à maneira de falar com os superiores e também com os inferiores e o que não deveria ser dito a todos aqueles que estavam fora das conversações. A espontaneidade foi encorajada sim, mas também havia advertências de como ela deveria ser produzida. Cooperação - sim, mas logo os manuais reconheceram a competitividade na conversação e o desejo de brilhar . O historiador Peter Bruke (1995) conclui que "a verdadeira teoria geral da conversação deveria discutir a tensão e o equilíbrio entre competitividade e os princípios cooperativos, entre igualdade e hierarquia; inclusão e exclusão e entre espontaneidade e estudo, em vez de se colocar todo o peso nos primeiros itens de cada um dos pares citados acima"(p. 92).

Reconhecer a tensão entre os princípios da conversação é uma forma de chegar a uma visão mais coerente e realista da mesma. Eu proponho, de forma alternativa, que dois diferentes ideais da conversação sejam entrelaçados e confusos. Um ideal poderia ser denominado como o modelo social da conversação, e o outro como o modelo que resolve-problemas. A característica que os diferenciaria do ideal social seria a insistência da conversação ser nãoutilitária. Em uma conversação, como filosofia política, Michael Oakeshott escreveu que o desejo não é investigado e que não existe aspiração a uma conclusão. Nem mesmo a informação ou a persuasão são cruciais. Racionalizando "não há eficácia" e a conversação "não compõe um argumento". A conversação não tem um fora de si mesmo. É "uma aventura intelectual que não foi ensaiada" e "assim como uma aposta, existem as significativas mentiras ao ganhar ou perder, mas só se sabe quando se arrisca" (Oakeshott, 1962, p. 198; ver também Shapin, 1994, pp. 114123). ${ }^{3}$ 
A parte de maior repercussão da discussão de Oakeshott sobre a conversação é a sua noção de que os seres humanos de uma determinada era herdaram da civilização não a ciência ou a tecnologia ou até mesmo um acúmulo de conhecimento, mas sim "a conversação que se iniciou nas florestas primitivas, se estendeu e sofreu muitas articulações através dos séculos". É a conversação que "caminha" em ambos, no povo e dentro de cada um de nós. É a habilidade de participar nestas conversações - e a não habilidade de ser convincente - é fazer descobertas sobre o mundo, ou de inventar um mundo melhor, é que diferencia o ser humano do animal e o homem civilizado dos bárbaros (p. 198). Então, neste modelo a conversação é orientada para a satisfação da interação com outros em uma mesma conversação; é portanto con temporaneamente social. Mas, além disso, como parte de uma conversação contínua além do tempo, colher material de um longo termo de tradição humana é também historicamente social.

Contrastando, a compreensão da conversação que resolve-problemas encontra a justificativa da fala na sua relação prática com a articulação de finais em comum. Voto popular, regras estabelecidas pela maioria e outros índices da democracia são válidos, segundo John Dewey, pelo fato de que "eles envolvem consultas e discussões que transparecem problemas e necessidade sociais“(1927, p. 206). O problema central para a democracia moderna é a face do desenvolvimento nos métodos e condições de debate, discussão e persuasão. Este é o problema do povo (p. 208). Para Dewey, a democracia não poderia existir sem a participação e a conversação era a marca de entrada da participação. "A conexão da audição com o pensamento livre, vital, e com a emoção é imensamente mais próxima e variada do que aquela feita através da visão. Quem vê é um espectador, quem ouve é um participante“(p. 219) ${ }^{4}$ Para
Carey também, embora em uma linha de seus pensamentos ele escreva quanto à atração do puro prazer da fala e a ênfase na conversação como se fosse o local onde a democracia acontece, se é que ela realmente acontece.

A conversação, para Carey, é uma disputa em torno da notícia, uma discussão sobre as questões de nosso dia-a-dia. Fica de um lado para o outro, fora do que a própria democracia pública realiza. Carey, em alguns temas, critica Dewey, particularmente na sua forma de pensar através das questões do poder presente na fala, e também na desconfiança de Carey quanto aos experts na democracia que não estão aos termos que Dewey acredita como fundamentais para o conhecimento da vida democrática. Mas, no geral, a voz de Carey nos estudos da comunicação tem sido campeã na relevância da visão de Dewey para a sociedade contemporânea (ver Carey, 1989, pp. 69-88). Ambos os modelos de conversação, o social e o que resolve-problemas, enfatizam a igualdade dos participantes da conversação. Dentro da conversação, a igualdade, a civilidade e a justiça predominam. Mas os limites para a entrada nesses modelos diferem. O modelo social enfatiza o culto e a sensibilidade, participantes da conversação devem desenvolver capacidades sutis para avivar e entreter no que corresponde à fala. $\mathrm{O}$ modelo que resolve-problemas, em contraste, focaliza o argumento. As capacidades dos participantes da conversação devem formular e responder a visão afirmativa daquilo que o mundo é, ou gostaria de ser. O modelo social vê a conversação como algo que "fala por si", é "estético". O modelo que resolve-problemas vê a conversação como o significado de um bom governo. De formas mais forte, mostra a conversação por ela mesma, como modelo do bom governo. A habilidade ou capacidade de uma participação competente da conversação na sociedade é uma facilidade verbal, uma aptidão, e também a própria 
sociabilidade. A capacidade do participante no modelo que resolve-problemas é justa - como coloca o teórico Willian Galston, é "tanto a prontidão para ouvir uma série de pontos de vista" quanto "a prontidão de concordar com um ponto de vista de forma cândida e inteligente assim como base da persuasão política"(1991, p. 227).

A natureza interativa e recuperadora da conversação o tomam particularmente apto a ser modelo, por um lado da sociabilidade e por outro do raciocínio público. Assim como o seu essencial caráter cooperativo. Mesmo em um argumento, existe o apoio mútuo - se somente na concordância fica-se engajado para continuar focalizando outra pessoa e não abandonar a fala, usando a hostilidade ou através do "tratamento de silêncio". Mesmo em uma troca hostil, os "princípios cooperativos" do filósofo Paul Grice (1975/1989) são satisfatórios para que os participantes falem de acordo com as "propostas e direções aceitas das palavras a serem trocadas" na conversação à qual estão comprometidos.

$\mathrm{Na}$ conversa social, o compromisso interativo da fala oferece a qualidade de um jogo riquíssimo - o xadrez - com muita coação, mas com um pouco de habilidade na previsão de resultados.

Do mesmo modo, o mérito comunicativo da conversação que resolveproblemas não é falar ou escutar e nem mesmo a proximidade entre os dois. É a interação dos participantes e a progressão da capacidade de cada declaração a ser revisada de acordo com as sugestões e respostas dos outros participantes.

Isto, por sua vez, depende de um grau de bom comprometimento. Um argumenta fora de controle leva a ambigüidade das declarações a serem lidas de forma mais hostil possível.

Se o marido e a mulher estão brigando, e um deles diz "eu não consigo mais agüentar, eu vou embora", o outro responde: "Então você não me ama mais? Você quer o divórcio? Você está me deixando?" Talvez a resposta mais lógica seria: "Veja bem, talvez nós dois deveríamos esfriar a cabeça um pouco". Só que o fato das pessoas estarem dialogando não significa que vão tirar vantagens do poder reparador que a conversação possui. Não pelo simples fato de dialogar, mas as normas que possui fazem da conversação útil para tornar um governo democrático por ele mesmo.

Existem muitas coisas entre a conversação e um governo democrático. E é por causa disso que as regras básicas da conversação são mais importantes que a espontaneidade que pode aparecer nele. A conversação sem educação e treinamento apropriados e sem igualdade social pode ser, e normalmente é, desigual. As regras da conversação democrática podem ajudar a proteger a lentidão da linguagem, que de certa forma priva os direitos civis pela articulação e pela fluência.

Falando nisso, uma reunião de uma cidade acaba por ser uma tarefa das mais difíceis, porque algumas pessoas sentem tanto medo que simplesmente não vão.

Como disse um fazendeiro em Vermont, para a cientista política Jane Mansbridge (1980, pp. 6064), "...isso requer um pouco de coragem, especialmente se você levanta e faz uma besteira. Eu quero dizer, se você se engana e diz alguma coisa errada, aí a pessoa não se levanta para dizer mais nada. E eles acabam por se sentir inferiores ". Florence Johnson, uma empregada doméstica e mãe de cinco filhos, nunca havia ido a nenhuma das reuniões de sua cidade quando Mansbrigde conversou com ela. Disse que: "Se você for e falar, as pessoas vão gozar de você e assim será sempre, então eu acredito que as pessoas não compareçam para não serem gozadas pelos outros". Alguns acham que as pessoas devem falar somente se estiverem zangadas com algo. Um homem de negócios já aposentado disse: "Algumas pessoas são eloqüentes e fazem as outras se sentirem inferiores. Elas podem colocar as pessoas para baixo. 
Eu não diria uma palavra em uma reunião destas, a ser que me deixassem muito irritado".

Cada vez mais Mansbrigde vinha observando que havia muita tensão em torno destas reuniões, ou, como para alguns cidadãos, este é o real prospecto destas reuniões. A fazendeira Jamie Pedley teve uma forte dor de cabeça, um homem mais velho temeu o seu próprio coração. Cada vez mais as pessoas da cidade reportam que não querem falar nestas reuniões porque têm medo de ser criticados ou de passar por ridículos.

Mesmo para aqueles que superam seus medos e vão a estas reuniões, a prontidão para falar é desigualmente distribuída.

Esta distribuição reproduz e até mesmo acentua as desigualdades sociais. Por exemplo, $49 \%$ daquelas pessoas que foram às três reuniões que Mansbrigde organizou eram mulheres, mas somente $29 \%$ delas falaram e mesmo assim foi para fazer perguntas ou apresentar resultados. Só $8 \%$ das mulheres representaram 0 que Mansbrigde chama de "declarações principais de opinião." E não iniciaram nenhuma das trocas de controvérsias.

O medo de ficar envergonhado, que os cidadãos de Vermont expressam, é uma característica humana fundamental. Charles Darwin disse que cada expressão humana de emoção, exceto uma, tem uma reação análoga em outra espécie. A mais característica manifestação humana de emoção é a de ruborizar-se, de envergonhar-se. Darwin explica que é "aquilo que os outros pensam de nós que excita o aparecimento do vermelhidão no rosto". Nós ficamos vermelhos por estarmos em situação embaraçosa. Para o sociólogo Erving Goffman (1981), o esforço que fazemos para evitar tais situações é o drama central e contínuo da vida social humana. Não é mera coincidência que as situações que Goffman regularmente analisa são as públicas. Existem situações em que a possibilidade de embaraços é mínima, particularmente quando as pessoas se sentem em casa, ou onde religiosos ou políticos ou a paixão de Mara faz com que as pessoas sejam praticamente antisociais, ou seja, completamente insensíveis às opiniões de meros conhecidos ou estranhos. Mas em reuniões públicas, em conversas nas ruas, e quaisquer outras interações com conhecidos do público, a apresentação da pessoa e o risco de passar por uma situação embaraçosa vem à tona (ver Schudson, 1984).

Nós devemos distinguir dois tipos de conversações na democracia, ambos necessários, mas radicalmente diferentes para o funcionamento da sociedade democrática. Em uma conversação homogênea, as pessoas conversam primeiramente com aquelas que compartilham os mesmos valores e esperam que a conversa vá reforçar os pontos de vista do que elas já compartilham. Neste tipo de conversação as pessoas testam suas opiniões, para que tenham certeza do que concordam e se arriscam a dar idéias que podem não ser calorosamente aceitas, mas o fazem sob um grande conhecimento de que concordam no que é fundamental e que a suposição daquilo que compartilham fará com que tal experimentação seja segura. As pessoas talvez estejam preparadas para estes diálogos familiares de sua cidadania na forma mais assustada de um diálogo heterogêneo. Aqui, o que podemos chamar de diálogo do "público real", os cidadãos falam de outros cidadãos que talvez não compartilhem de seus pontos de vista e seus valores. Neste tipo de diálogo, teste de amizade é tudo, menos impossível; nestas direções, existem penalidades por expressar incerteza e dúvida, prêmios por expressar incerteza e dúvida, prêmios por expressar convicção e certeza. Temperamentais podem enfurecerse e parceiros de trabalho podem ser atemorizados ou severos. Mas também pode haver a alegria de executar acordos (ou, tanto de um lado como de outro, 
abertura para concessões) e na face da dificuldade do diálogo heterogêneo a busca que o trabalho do povo seja feito. ${ }^{5}$

É especialmente no diálogo do público real que as normas da razão são mais imploradas. Stephen Macedo (1990), por exemplo, disse que a opinião na democracia obrigatoriamente deve ter "uma certa forma e qualidade de racionalismo" se for para ser formada pela força do povo. No mínimo os cidadãos devem ter razões públicas e argumentos para apoiar as suas ações políticas". "Estas razões públicas devem ser adicionalmente disciplinadas pelo contato com os aspectos racionais e defensivos de nossa constituição e tradição legal." (p. 103).

Macedo pretende mostrar que o liberalismo é compatível com a relativa noção de cidadania, que é um dos acertos e virtudes do requerimento dos cidadãos na sociedade. "Cidadãos devem participar do espírito da justificativa pública: não simplesmente colocando as suas próprias posições, mas considerando e levando em conta as razões dos argumentos dos outros, incluindo aquelas dos oficiais públicos." Liberalismo, segundo Macedo, não surgiu só para a tolerância, para leis governamentais de liberdade e noções de justiça centradas nos direitos, mas também para um "próprio governo nacional". O que insiste que nos tratemos uns aos outros com racionalidade e que encontremos as diferenças "com o uso da razão" é uma "aspiração da racionalidade pública" (p. 40).

O ponto de vista de Macedo se diferencia de ambos os modelos de diálogo social e aquele que resolve-problemas que eu havia citado. Diferentemente da visão social, é quase que incrivelmente cerimonial, fervorosamente visível, uma conversa orientada para chegar a um senso comum e operada pelas mais rigorosas normas da moralidade pública. A estética pode jogar, mas a inteligência fica de fora. Ao mesmo tempo, esta visão distinguese de qualquer outro modelo que enfatize a espontaneidade no diálogo. O diálogo imaginado por Macedo, não é espontâneo, nem volúvel, nem mesmo fluente. É um diálogo difícil. As suas virtudes mentem tanto na preparação do diálogo quanto em qualquer tipo de espontaneidade que possa surgir, ou certamente qualquer coisa que possa ser consumada através da discussão por ela mesma. Isto também é verdade na teoria geral de Bruce Ackerman. Ackerman afirma que a conversa é "a primeira obrigação do cidadão " (1989, p. 6).

Ackerman coloca, de forma correta na minha opinião, que o liberalismo não foi fundado em um aspecto liberal, ele é a autonomia individual e racional que expressou opinião quanto à ciência da razão, e portanto implicou a classificação do homem branco de classe média e boa moral.

O Liberalismo no sistema deu motivos àqueles socialmente acomodados que constituem a sociedade, ou seja, pessoas que têm regras diferentes, que têm aspectos diferentes e que agem de formas diferentes em situações diferentes. Nas direções da política pública, tais pessoas vivem no passado ou presas de certa forma a si mesmas. Elas não se enquadram no liberalismo porque elas foram construídas exatamente para isso; elas fazem parte dele porque é dever delas fazer com que ele funcione. As normas que são razoáveis, como aquelas que Macedo acredita, não são incorporadas dentro de nenhum diálogo. Pense nas regras de diálogo de Grice que Habermas adota em seus diálogos costumeiros. Estas são regras de cooperação ao contrário das regras razoáveis. Elas requerem menos relação lógica na conversa - para subordinar qualquer agenda pessoal a continuar o diálogo por ela mesma como a concordância que está havendo entre os participantes.

Segundo Erving Goffman, "falar é um exemplo do que um acordo onde indivíduos ficam juntos e suportam problemas tendo uma confirmação, uma articulação, uma corrente e exigindo atenção, exigências as quais os colocam juntos sob uma certa 
forma de mundo mental intersubjetivo" (1981, pp. 70-71).

Esta é a definição do diálogo de uma forma bastante cercada, mas não especifica condições suficientes para os teóricos democráticos apoiarem-se. Muitas cooperativas bem-sucedidas caem sobre um ideal democrático. Harold Pinter, em uma pequena peça chamada "A dor da desdenha", reproduz em uma mesa de café da manhã uma conversa entre Flora e Edward. Edward, como nós já devíamos esperar, está lendo o jornal no começo da cena, mas Flora tenta manter uma conversa com ele:

FLora: Você notou a madressilva esta manhã?

EdWARD: Notei o quê?

FLORA: A madressilva?

EDWARD: A madressilva? Onde?

FLORA: Perto da porta dos fundos, Edward.

EdWARD: Aquilo é madressilva? Eu achava que era uma ipoméia ou algo assim.

Flora: Mas você sabe o que é uma madressilva?

EDWARD: Eu te disse que achava que era uma ipoméia (pausa).

FLORA: É uma linda flor.

EDWARD: Eu tenho que ir ver.

FLORA: Todo jardim está florido esta manhã. Os botões de ouro. As ipoméias. Todas. Eu estava lá fora às sete. Eu fiquei parada da piscina observando-as.

EDWARD: Você disse que as ipoméias estavam floridas?

FLORA: Sim.
Edward: Mas meu Deus, você acabou de negar que ela tinha dado flor.

FLORA: Eu estava falando da madressilva.

EdWARD: De quem?

FLora: (calmamente) Edward, você sabe aquele arbusto fora da barraca de ferramentas?

Edward: Sei, sei.

Flora: Aquelas são ipoméias.

EdwARD: Aquelas?

FLORA: Sim

EDwARD: Oh! (pausa) Eu achei que fossem minirrosas.

Flora: Ai, meu Deus do céu, não são, não.

EdWARD: Me passa o bule, por favor. ${ }^{6}$

Bem engraçado como parece, este diálogo possui todo um modelo das questões e características de uma conversação. Tem um engajamento mútuo. É equilibrada, igualitária, possibilita troca. Possui o "dar e receber" que impossibilita o reparo ou a recuperação de tomar lugar. Tem o poder de transmitir informações e esclarecimento em palavras comuns. Mas não possui razões públicas.

As razões públicas são necessárias onde a tranqüilidade pessoal é posta em risco. É claro que a conversação é importante em um cenário confortável, onde nós podemos mostrar aquilo que acreditamos como se "pensássemos em voz alta". Mas também é importante - cenário desconfortável, onde há risco de ficarmos embaraçados se não soubermos ou não conseguirmos articular aquilo que acreditamos. Desta forma, os cenários desconfortáveis predominam nas discussões das instituições 
públicas. A democracia é profundamente desconfortável. Certamente na democracia pública o cenário onde a ansiedade se retorce, o mundo de Goffman é que toma frente.

\section{O assunto da democracia}

Agora, qual é o assunto da conversação que resolve-problemas em uma democracia? A substância da conversação deve ser próxima à irrelevância do modelo social - exceto por não dever nunca ser sobre problemas o bastante para dilacerar a sociabilidade. O modelo que resolveproble mas é mais ambicioso e mais cheio de conflitos. Ele insiste em um grau de sociabilidade ou, pelo menos, de civilidade, mas também na capacidade que a conversação tem de traduzir o social para o público. Também traduz o público para o social. A conversação democrática é em parte dependente da primordial existência da palavra pública geralmente disponível na imprensa. Isso reforça a visão expressada há um século pelo sociólogo francês Gabriel Tarde, cujos livros e jornais oferecem substâncias aproximadamente universais das conversações privadas. Não é que todos precisem ler jornais, mas a maioria daqueles que falam é forçada a seguir a rotina dos pensamentos emprestados a eles. "Uma caneta é suficiente para escrever um milhão de línguas" (1898/ 1969 , p. 304). Antes da imprensa, segundo Tarde, a conversação foi variando muito de um lugar para outro e teve em comum somente a sua monotonia. Mas com livros, e especialmente as pressões, a conversação se tornou "uniforme no espaço e diversificada no tempo". Todas as manhãs os jornais dão aos seus leitores os assuntos para as suas conversas do dia. Um deles pode ser certamente usado em qualquer momento de uma conversação entre homens no clube, em uma sala de fumantes, em um hall (1898/1969, p. 312).

O jornal, Tarde acrescenta, "começa simplesmente como um item prolongador de conversas e correspondências e acaba quase como uma fonte exclusiva" (pp. 317318). A conversa democrática centralizase nos problemas públicos. Isto também significa, eu acredito, que as conversas democráticas são sobre o que vem das fontes públicas. O jornal é historicamente a fonte central da conversação democrática - o jornal, as leis, o mundo público.

Existem muitas linhas de pensamento hoje em dia sobre a massa da população, que assume que a conversação face a face é uma forma superior de interação humana para a qual a comunicação em massa é sempre substituída de forma falha.

Como John Dewey escreveu em 1927, "as palavras que voam em uma conversação em um imediato comércio têm importância vital na carência das palavras fixas e congeladas de um discurso escrito". Dewey reconheceu que a imprensa é necessária, uma "precondição para a criação de um público verdadeiro". Até mesmo "ela e seus resultados são como ferramentas ao final. As finalidades reais são treinadas nos relacionamentos cara a cara pelo significado direto do "dar e receber" (p. 218).

Estas são tentativas de salvar a superioridade da conversação sobre a comunicação em massa, mas eu não acho que obtenham sucesso. A conversa democrática, apesar de tudo, é geralmente o inverso do que Dewey (e após ele, Carey) sugere: a conversação cara a cara nos leva para algo que foi escrito, ao contrário da impressão culminante de algo que se converse. A consumação da conversa democrática talvez seja uma petição assinada, uma notícia postada, uma lei escrita, uma opinião judicial escrita, uma ordem executiva escrita. A democracia coloca muitos mantimentos no poder da escrita para assegurar, verificar e formar o público. A democracia requer memórias públicas; escrever maravilhosamente engrandece as memórias públicas. Então, falar em democracia é civil, público e 
orientado para a explícita, disponível e transportável comunicação encontrada para a impressão e emissão, ao contrário da conversação cara a cara.

A conversação na maioria das vezes é o DNA ou o plasma da vida social. Tem a capacidade de se duplicar, de se combinar, de se exceder. Essencialmente, não é nem pública, nem privada, mas sim social. Existe não só na democracia. A conversação na democracia pode diferir da conversação em outro lugar, não porque a democracia transborda conversação, mas porque as normas e instituições da democracia política ensinam e formam as versões para começarem assim. Nada em uma conversação necessariamente sugere a democracia, nem mesmo na sua forma de igualdade. Na Europa moderna, foi sugerida a aristocracia, porque ela depende do cultivo.

Pode ser que a democracia estabeleça normas que afetam até mesmo a homogeneidade da conversação familiar na democracia. A cidadania filtra do fórum da política comum para as suas elaborações privadas. Onde isto acontece, por exemplo na família, fica difícil para os pais perguntarem aos seus filhos: "Por que eu deveria?" E como resposta ouvir um "porque eu disse."

A norma de dar razão compete com a arrogância da autoridade paterna. A democracia criou a conversação democrática mais do que a conversação natural criou a democracia. Como o filósofo George Kateb sugeriu, a democracia cultiva um certo tipo de pessoa, súbita, incompleta, mas não menos efetiva. A mera "condição do cidadão", ele escreveu, deve fazer uma pessoa conveniente para correr para o escritório, ou para votar, é "um estímulo contínuo à reclamação da condição do cidadão... em todas as manipulações das relações da vida". Desta forma, o estímulo é de politizar o monopólio das relações da vida e assim, democratizá-las (Kateb, 1992, p.40).

A conversação democrática prevê pouca igualdade e espontaneidade como uma ordem normativa que insiste nas ordens sociais e iguais, que por sua vez, insistem em um certo nível de publicidade em suas conversações. Ou seja, a conversação democrática é uma conversação que não ocorre entre íntimos e nem mesmo entre estranhos, mas entre cidadãos que são informados de sua cidadania. Estranhos vão ter dificuldade de se comunicar porque eles não compartilham o mesmo cenário de comprometimento e conhecimento de normas; os íntimos vão se comunicar sem precisar falar, sem pedir permissão, sem atingir um potencial de conflitos ou embaraços. A conversação democrática, em contraste, irá facilitar a comunicação pública dentro das normas das razões públicas, não simplesmente como uma facilidade de interação social.

A conversação social é utilizada entre iguais, não necessariamente íntimos, em clubes e cafeterias. Onde a conversação democrática é usada é bem mais difícil de indicar. Talvez seja em uma discussão de valores entre íntimos em uma família. Mas a totalidade da conversação democrática é usada, como eu havia sugerido, em situações onde a fala é destinada a ser desconfortável. Este é um tipo de conversa onde as pessoas não toleram o engajarse; é um convite ao conflito, e seja numa cidade pequena como Vermont, ou qualquer outro lugar, as pessoas preferem conversas sociais àquelas potencialmente explosivas. ${ }^{7}$ Tanta conversa é uma ameaça grande o bastante que requer regras formais ou informais de engajamento. Veja, por exemplo, as regras estabelecidas para as conversas na convenção Constitucional "Ur-conservation" dos Estados Unidos.

Em 1787, dia 25 de maio, uma sexta-feira, a convenção Constitucional se reuniu pela primeira vez. A sua abertura de negócios foi prontamente manejada por George Washington, que havia sido selecionado como presidente da convenção, e um comitê ficou encarregado de preparar os procedimentos, incluindo 
o de que quando um dos membros destes encontros estivesse discursando nenhum dos outros presentes poderia falar com outro membro, ou "ler um livro, panfleto, papel, jornal ou manuscrito". Ninguém poderia falar mais do que duas vezes sobre a mesma questão sem uma permissão especial e só poderia falar pela segunda vez depois que todos os outros membros que desejavam falar já haviam tido a sua chance. Estas regras de respeito e igualdade mútua para participações foram suplementadas por regras que encorajavam a consideração deliberada das questões tratadas, eram regras para a razão pública. Uma questão complicada podia ser dividida ao pedido de qualquer um dos membros. Qualquer questão poderia ter um voto adiado até o dia seguinte, mesmo que o debate já estivesse concluído. Qualquer documento escrito, para ser aceito, deveria ser lido uma vez e então ser debatido por parágrafos. Regras de civilidade também foram propostas. Qualquer membro poderia ser chamado por qualquer outro membro e desta forma ele teria "permissão para explicar sua conduta ou expressão e também sabia que poderia ser repreendido". O presidente era quem iria decidir as questões de ordem sem apelar para o debate.

Todos os comitês propuseram regras com uma aprovação geral, exceto uma: havia uma objeção a uma proposta de que cada membro poderia anunciar os votos prós e contras e tê-los registrados em minutos. Os atos da convenção não tinham obrigação moral para com os representantes da convenção. De qualquer forma, Rufus King, de Massachusetts, relembrou a convenção, e então foi desnecessário mostrar aos membros o voto deles. George Mason adicionou que guardando provas escritas dos votos iria criar uma dificuldade para os membros modificarem seus votos, mesmo que suas convicções tivessem se modificado. Mason, um psicólogo social muito astuto, sugeriu que os votos guardados iriam forçar as pessoas a se prenderem na sua própria consciência, mesmo quando a razão permitisse mudar de opinião. Além disso, Mason ainda diz que esta "gravação dos votos" seria uma arma nas mãos dos adversários após os resultados da Convenção. Tais objeções ganharam o dia.

Todas estas sugestões, eu acho, fizeram com que o diálogo democrático não fosse livre, igual e espontâneo nas suas expressões, mas de igual acesso ao discurso na convenção, na participação igual de regras para a discussão, e um cenário de regras formulado para encorajar o discurso de propósito oportuno, a escuta atenta, as simplificações apropriadas e a ampla divisão da fala correta. A primeira política de dialogo americana foi cuidadosamente estruturada para que através dos limites de dezoito séculos que contaram com cidadania pudesse ser deliberadamente genuína e democraticamente genuína. E também para ser qualquer outra coisa, exceto espontânea.

\section{Conclusão}

A conversação não oferece nenhuma solução mágica para os problemas da democracia. A democracia tem um pouco a ver com intimidade e com comunidade. Pode ser emocionante, pode ser cansativa, pode provocar ansiedade e também ser desconfortável. Eu raramente gosto de um discurso deliberativo de assembléias públicas em meio a tantos para tomar decisões. Eu prefiro a conversação entre duas pessoas a grandes reuniões. Eu prefiro seminários a grandes assembléias. Quanto maior o grupo, mais eu quero regras de engajamento, porque eu sou lento nos meus discursos. Esta é a parte do porquê a conversação romântica fica difícil de ser compreendida.

Tem outra coisa que eu gostaria de acrescentar. A conversação romântica falha no entendimento. A democracia, em 
alguns casos, requer o desvio dos assuntos públicos comuns. Democracia, segundo Stephen Holmes sugere (1995, pp. 202235) talvez insista que até mesmo falar seja uma restrição. ${ }^{2}$

Nos Estados Unidos, os perigos de uma desunião e de um desmembramento do governo e da sociedade civil pela paixão religiosa levaram a criação da Primeira Emenda e agora uma história de 200 anos de esforços científicos Constitucionais para manter a religião fora das discussões políticas. A democracia pode, de certa forma, escolher calar as deliberações políticas, e removê-las para a sociedade civil ou para a esfera privada. A democracia ainda pode escolher calar diretamente o discurso político dentro dos interesses da deliberação da justiça da mente. O exemplo mais familiar disso aconteceu por todo os Estados Unidos. Foi uma proibição do discurso político dentro de uma certa distância especificada dos locais de votos no dia das eleições. Aqui, o discurso é tratado como uma ação, como uma forma de intimidação ou como uma forma injusta de tirar vantagem. Legisladores por todo o país concluíram que o foco do silêncio político deve circundar o castelo dos locais de voto. Os eleitores têm seus passos direcionados para as tendas de voto, com seus direitos coletivos de expressão sacrificados pelos seus direitos individuais da deliberação pessoal.

A democracia deve retirar-se da civilidade por ela mesma. A democracia algumas vezes requer que 0 seu interlocutor não espere educadamente que você termine mas que você puxe pelo colarinho e grite: "Escute, escute, pelo amor de Deus!"

Nós chamamos isso de situações de movimentação social, surpresas, demonstrações.

Nós chamamos as pessoas que iniciam tantas saídas da direção civil, de ambiciosas, irracionais, egoístas, rudes, pessoas de cabeça quente, aquelas do tipo Newt Gingrich e Martin Luther King e Willian Lloyd Garrison. Todas estas pessoas desejando se engajar na conversação democrática, mas também brigando através do ponto da civilidade, até mesmo desejando fazer do caso deles uma opção para sair da conversação inteiramente, pelo menos temporariamente ou estrategicamente. Qualquer conceito completo de democracia ou de local de conversação deverá ter que considerar os instantes onde o diálogo é por ele mesmo um impedimento para o cumprimento da democracia .

(Artigo publicado originalmente em Critical Studies in Mass Communication 14, 1997, 297-309. Publicação em português aprovada pelo autor. Tradução de Viviane Jadoski Lucas de Oliveira)

\section{Notas}

1 A definição foi adaptada por A. D. Lindslay em Holmes, 1995, p. 71.

2 Burke (1995, p.106), citando manual de 1672, de Charles Sorel.

3 Gabriel Tarde também diz que a conversação não é utilitária. Ele a define como qualquer conversação sem direção e utilidade imediata, onde se fala só por falar, só por prazer, como um jogo, sem politicagem. (Tarde, 1898/1969, p. 308). Isto foi extraído de Tarde, L'opinion et la foule (Paris, Alcan, 1922, pp. 62-158), mas foi primeiramente publicado no Reveu de Paris, em 1898. Ver a nota em Tarde, 1898/1969, p. 297.

4 Oakeshott provavelmente não tinha utilidade aos experts: não tinha nenhuma característica de sabedoria, que é preciso na participação de uma conversação. Há o culto, mas isso é bem diferente. Mas se Oakeshott não é um admirador da sabedoria, Dewey é quase que diretamente crítico: "É impossível para altos testes assegurar 0 monopólio de tanto conhecimento a ser usado na regulação das habilidades comuns. No grau em cada um freqüenta uma aula especializada, eles são retirados do conhecimento, das necessidades que cada um está suposto a servir".

5 Eu desenvolvi esta distinção das sugestões feitas por Katz. 
6 Eu usei esta cotação há alguns anos em um novo e muito diferente esforço para entender a conversação ao pensar na mídia de massa, e depois na democracia.

7 Conversa política no cenário público pode até mesmo ser ridicularizada, como no início do século, por tomar o lugar turbulento da rua, em vez do cenário civil de uma casa. Um jornal de New Jersey glorificou o "silêncio, homem pensando..." que segue silenciosamente dia após dia nos seus negócios, ganhando subsistência e que à noite é encontrado em sua casa, em vez de estar falando de políica nas esquinas. Trenton True Americam, November 6, 1911, citado em Reynolds, 1988, p.120.

\section{Referências}

CAREY, J. (1995). "The press,public opinion, and discourse", in T. Glasser \& C. Salmon (Eds.), Public opinion and the communication of consent (pp.373-402). New York: Guilford.

DEWEY, J. (1972). The public and its problems. New York: Henry Holt.

GALSTON, W. (1991). Liberal purposes. Cambridge University.

GOFFMAN, E. (1981). Forms of talk. Philadelphia: University of Pennsylvania.

GRICE, P. (1989). "Logic and conversation". In P. Grice, Studies in the way of words. Cambridge, MA: Harvard University.

HABERMAS, J. (1974). "The public sphere". New German Critique, I, 49-55.

HOLMES, S. !995). Passions and constraint. Chicago: University of Chicago.

KATEB, G. (1992). The inner ocean. Ithaca, NY: Cornell University.

MANSBRIDGE, J. (1980). Beyond adversary democracy. New York: Basic Books.

OAKESHOTT, M. (1962). "The voice of poetry in the conversation of mankind". In M. Oakeshott, Rationalism in politics. New York: Basic Books.

PINTER, H. (1962). A slight ache. Three plays. New York: Grove.

REYNOLDS, J. (1988). Testing democracy. Chapel Hill: University of North Carolina.

SCHUDSON, M. (1984). "Embarrassment and Erving Goffman's idea of human nature". Theory and Society, 13, 633-648.

SHAPIN, S. (1994). A Social History of Truth. Chicago: University of Chicago.

SIMPSON, D. (1995). The academic postmodern and the role of literature. Chicago: University of Chicago. 75-85.

D. (1997)."The cult of çonversation". Raritan, 16,

TARDE, G.(1898/1969). On communication and social influence (T. Clarck, Ed. \& Trans.). Chicago: University of Chicago. 